\title{
Hortfértil: planilhas para interpretação da análise de solo e recomendação de adubação para hortaliças
}

O desenvolvimento de planilha eletrônica voltada para a recomendação de adubação permitirá trabalhar os dados de forma tecnicamente correta, com maior simplicidade e rapidez. Nesse contexto, o presente trabalho objetivou desenvolver um conjunto de planilhas eletrônicas para recomendação de fertilizantes orgânicos e minerais para hortaliças de importância socioeconômica no Estado do Maranhão. O conjunto de planilhas, denominado Hortfértil, foi criado utilizando o Microsoft Excel, devido sua capacidade de trabalhar com operações numéricas, e ser possível aplicar funções para modelagem dos dados. O Hortfértil realiza a recomendação de corretivos e fertilizantes para as culturas: milho verde, quiabo, feijão verde, melancia, cebolinha, coentro, alface e couve-folha. Para cada cultura foram elaboradas duas planilhas, sendo uma de cálculo (não visivel para o usuário) e uma de apresentação, onde o usuário insere o nome do produtor, o espaçamento da cultura, o tamanho da área a ser cultivada, o PRNT do calcário a ser utilizado, escolhe os fertilizantes e tem como saída os valores recomendados. As planilhas realizam a recomendação para dois anos de cultivo em função da percentagem de mineralização no decorrer do tempo. Para realizar o cálculo de recomendação da adubação foi utilizada a ferramenta 'Solver' para encontrar a melhor combinação de fertilizantes de acordo com a exigência da cultura. Ao final do processo de recomendação da adubação, o resultado pode ser impresso ou salvo em PDF na área de trabalho. O Hortfértil apresenta-se como uma ferramenta promissora na recomendação de adubação orgânica e mineral para hortaliças. Devido sua complexidade de funcionamento exige um grande período de avaliação e experimentação para poder ser comprovada sua aplicabilidade e eficiência na recomendação de fertilizantes.

Palavras-chave: Excel; Organomineral; Hortaliças; Fertilizantes.

\section{Hortfértil: spreadsheets for the interpretation of soil analysis and fertilization recommendation for vegetables}

The development of an electronic spreadsheet aimed at recommending fertilization will make it possible to work with the data in a technically correct way, with greater simplicity and speed. In this context, the present work aimed to develop a set of electronic spreadsheets to recommend organic and mineral fertilizers for vegetables of socioeconomic importance in the State of Maranhão. The set of worksheets, called Hortfértil, was created using Microsoft Excel, due to its ability to work with numerical operations, and to be able to apply functions for data modeling. Hortfértil recommends correctives and fertilizers for crops: green corn, okra, green beans, watermelon, chives, coriander, lettuce and kale. For each crop, two spreadsheets were created, one for calculation (not visible to the user) and one for presentation, where the user enters the name of the producer, the crop spacing, the size of the area to be cultivated, the PRNT of the limestone to be used, chooses the fertilizers and outputs the recommended values. The spreadsheets make the recommendation for two years of cultivation as a function of the percentage of mineralization over time. To calculate the fertilizer recommendation, the 'Solver' tool was used to find the best combination of fertilizers according to the crop's requirements. At the end of the fertilization recommendation process, the result can be printed or saved in PDF on the desktop. Hortfértil presents itself as a promising tool in the recommendation of organic and mineral fertilization for vegetables. Due to its operating complexity, it requires a long period of evaluation and experimentation in order to prove its applicability and efficiency in the recommendation of fertilizers.

Keywords: Excel; Organomineral; Vegetables; Fertilizers.

Topic: Desenvolvimento, Sustentabilidade e Meio Ambiente

Reviewed anonymously in the process of blind peer.

Klayton Antonio do Lago Lopes

Universidade Federal do Maranhão, Brasil

http://lattes.cnpq.br/2061482776415137

http://orcid.org/0000-0001-8645-4174

klaytonlopes2011@gmail.com

Taciella Fernandes Silva (iD)

Universidade Federal do Maranhão, Brasil http://lattes.cnpq.br/7439880565753613 http://orcid.org/0000-0001-9202-9668

taciellafernands@gmail.com

Ismênia Ribeiro de Oliveira (iD

Universidade Federal do Maranhão, Brasil http://lattes.cnpq.br/6056066450614670

http://orcid.org/0000-0001-9909-9925

ismenia.ribeiro.oliveira@gmail.com

d

DOI: 10.6008/CBPC2179-6858.2021.006.0046
Received: 06/06/2021

Approved: 28/06/2021

\author{
Jussara Silva Dantas (it) \\ Universidade Federal do Maranhão, Brasi \\ http://lattes.cnpq.br/3581069049274613 \\ http://orcid.org/0000-0001-5539-0366 \\ jussarasd@yahoo.com.br
}

Edmilson Igor Bernardo Almeida (iD)

Universidade Federal do Maranhão, Brasil http://lattes.cnpq.br/4485991332506597 http://orcid.org/0000-0003-2051-7085

edmilson i@hotmail.com
Referencing this:

LOPES, K. A. L.; SILVA, T. F.; OLIVEIRA, I. R.; DANTAS, J. S.; ALMEIDA, E. I. B.. Hortfértil: planilhas para interpretação da análise de solo e recomendação de adubação para hortaliças. Revista Ibero Americana de Ciências Ambientais, v.12, n.6, p.557-565, 2021. DOI: http://doi.org/10.6008/CBPC2179-6858.2021.006.0046 


\section{INTRODUÇÃO}

A produção de hortaliças exige planejamento na condução do cultivo com estratégias para minimizar perdas, aumentar a produtividade e reduzir os custos (ANDRADE et al., 2012). Uma alternativa viável é o uso de fertilizantes orgânicos, que além de reduzir as perdas e custos, pode propiciar o maior rendimento da cultura e qualidade da produção. Essa prática tem aumentado gradativamente nos últimos anos, tendo em vista o aumento nos custos dos fertilizantes minerais e a inerente capacidade destes em ocasionarem impactos ambientais negativos (PEREIRA et al., 2013). Atualmente, utilizam-se principalmente, recursos locais e subprodutos orgânicos que promovem o fornecimento de nutrientes e estimulam o ciclo biogeoquímico, através da decomposição dos compostos e resíduos orgânicos (LIMA et al., 2011).

A produção de fertilizantes orgânicos é considerada um importante artifício na produção de hortaliças (SEDIYAMA et al., 2014) e apresenta papel fundamental na sustentabilidade dos agroecossistemas, de forma a promover melhorias nos atributos físicos, químicos e biológicos do solo, com reflexos na estabilidade e na produtividade das culturas agrícolas (SEDIYAMA et al., 2016). Além de contribuir para o aumento da capacidade de troca de cátions (CTC) do solo e regular a disponibilidade de vários nutrientes, principalmente os micronutrientes (ZANDONADI et al., 2014).

Para manter uma boa produção, o ideal é aplicar uma adubação completa e combinada de fertilizantes orgânicos e minerais (ANDRADE et al., 2012), pois apenas o uso isolado do adubo orgânico pode causar excesso ou ausência de determinados nutrientes e não suprir a exigência da cultura. Bissani et al. (2008) ressaltaram que as baixas concentrações de N, P e K presentes nos fertilizantes orgânicos podem ser complementadas com adubação mineral, de maneira a ocorrer um melhor aproveitamento dos nutrientes, por meio do sincronismo de liberação ao longo do crescimento das plantas. Desta forma, torna-se necessário realizar a análise do solo e dos materiais orgânicos a serem empregados, para se determinar a composição química de cada um deles e posteriormente adotar práticas de manejo eficazes (SEDIYAMA et al., 2014).

Os recursos de tecnologias da informação (TI) podem otimizar as atividades agrícolas, inclusive aquelas voltadas para o manejo da adubação. O desenvolvimento de planilha eletrônica voltada para a recomendação de adubação pode permitir o processamento dos dados de forma tecnicamente correta, com maior simplicidade e rapidez, além de reduzir erros e o tempo gasto com cálculos.

As planilhas eletrônicas são utilizadas para processamento e armazenamento de dados em diversos campos de aplicações. Embora a adoção destas tecnologias por pequenos agricultores ainda seja bastante limitada (FERRAZ et al., 2017), os softwares aplicativos são bastante utilizados para apoiar as tarefas cotidianas de alguns produtores, tais como planilhas eletrônicas para recomendação de corretivos e fertilizantes paras as culturas do café (DIAS et al., 2011) e milho (SOUSA et al., 2011); para manejo de irrigação (NASCIMENTO et al., 2012); para gestão de insumos (AFFONSO et al., 2015), entre outros usos.

Nesse contexto, objetivou-se desenvolver um conjunto de planilhas eletrônicas para recomendação de fertilizantes orgânicos e minerais para hortaliças com importância socioeconômica no estado do Maranhão, levando em consideração as características do solo e a exigência nutricional da cultivar, de forma 
a otimizar o uso de insumos e manejo adequado da adubação.

\section{MATERIAIS E MÉTODOS}

O trabalho foi desenvolvido no Centro de Ciências Agrárias e Ambientais da Universidade Federal do Maranhão. O conjunto de planilhas eletrônicas, denominado Hortfértil, foi criado utilizando o Microsoft Excel, devido sua capacidade de trabalhar com operações numéricas e ser possível aplicar funções para modelagem dos dados, como realizado por Dias et al. (2011), Sousa et al. (2011) e Nascimento et al. (2012).

No hortfértil foi criada uma planilha exclusiva para preenchimento dos dados de análise do solo, cujos resultados foram importados para uso nas planilhas de recomendação de adubação. Utilizou-se o modelo de gráfico radar para criação de um fertigrama. A utilização do fertigrama permitiu a análise visual das concentrações de cada nutriente, bem como sua respectiva comparação com níveis críticos preestabelecidos (RIBEIRO et al., 1999).

Foram elaboradas planilhas de recomendação de corretivos e fertilizantes para as culturas: milho verde, quiabo, feijão verde, melancia, cebolinha, coentro, alface e couve-folha, de acordo com Ribeiro et al. (1999), Cravo et al. (2007) e Aguiar et al. (2014). Para cada cultura foram elaboradas duas planilhas, sendo uma de cálculo (não visível para o usuário) e uma de apresentação, onde o usuário pode inserir o nome do produtor, espaçamento da cultura, tamanho da área a ser cultivada, o PRNT do calcário a ser utilizado, escolher os fertilizantes e tem como saída os valores recomendados.

Para recomendação de adubação orgânica foi levado em consideração teores médios estabelecidos na literatura (Tabela 1). Entretanto, sabe-se que a maior dificuldade para caracterização dos fertilizantes orgânicos quanto a sua composição química e eficiência agronômica deve-se à grande diversidade destes, quanto à origem, grau de umidade e percentagem de conversão (RIBEIRO et al., 1999). Para complementar a adubação orgânica e fornece toda a exigência da planta, foram utilizados os fertilizantes minerais.

Tabela 1: Fertilizantes orgânicos e os teores médios dos nutrientes com base na matéria seca, encontrados na literatura.

\begin{tabular}{llllll}
\hline Fertilizante Orgânico & \multicolumn{2}{l}{ Umidade } & $\mathbf{N}$ & $\mathbf{P}_{\mathbf{2}} \mathbf{O}_{\mathbf{5}}$ & $\mathbf{K}_{\mathbf{2}} \mathbf{O}$. Autores \\
\hline Bagana de carnaúba & 10,00 & 2,10 & 0,15 & 0,40 & Morais et al. (2017) \\
Cinza de biomassa & 0,00 & 0,26 & 0,26 & 1,08 & Arruda et al. (2016) \\
Cinza de madeira & 0,00 & 0,11 & 1,14 & 6,71 & Sousa et al. (2017a) \\
Composto (esterco + resíduo vegetal) & 50,00 & 0,80 & 0,20 & 0,40 & Ribeiro et al. (1999) \\
Crotalaria juncea(folhas) & 86,00 & 2,00 & 0,60 & 2,90 & Traniet al. (2013) \\
Esterco bovino & 65,30 & 3,10 & 1,80 & 2,10 & Ribeiro et al. (1999) \\
Esterco caprino & 65,00 & 1,20 & 0,30 & 1,60 & Souza et al. (2017b) \\
Esterco equino & 70,50 & 1,80 & 1,00 & 1,40 & Ribeiro et al. (1999) \\
Esterco frango & 55,30 & 4,00 & 4,70 & 2,00 & Ribeiro et al. (1999) \\
Esterco ovino & 65,40 & 2,80 & 1,70 & 2,00 & Ribeiro et al. (1999) \\
Esterco suíno & 81,00 & 3,20 & 2,40 & 2,70 & Ribeiro et al. (1999) \\
Farinha de ossos & 6,00 & 4,10 & 27,30 & 4,30 & Traniet al. (2013) \\
Feijão guandu (folhas) & 85,00 & 1,81 & 0,59 & 1,14 & Kiehl (1985) \\
Feijão de porco (folhas) & 85,00 & 2,55 & 0,50 & 2,40 & Kiehl (1985) \\
Folha de mandioca & 85,00 & 4,35 & 0,72 & 0,00 & Kiehl (1985) \\
Mucuna preta (folhas) & 87,00 & 2,30 & 1,10 & 3,10 & Trani et al. (2013) \\
Torta de filtro (cana) & 72,00 & 1,20 & 2,20 & 0,50 & Ribeiro et al. (1999) \\
Torta de mamona & 9,00 & 5,40 & 1,90 & 1,50 & Ribeiro et al. (1999) \\
Turfa & 0,00 & 3,10 & 0,20 & 0,40 & Ribeiro et al. (1999) \\
Vermicomposto & 50,00 & 1,30 & 0,30 & 0,70 & Ribeiro et al. (1999) \\
\hline
\end{tabular}


Criou-se uma planilha de cadastro de fertilizantes orgânicos, na qual foi possível cadastrar um novo fertilizante ou alterar os já existentes. Para isso, criou-se "Macros" por meio do "Visual Basic Applications" (VBA), o que permitiu automatizar tarefas repetitivas (CINTO et al., 2008).

Para realizar a conversão da forma orgânica para a forma mineral utilizaram-se as percentagens de conversão disponíveis na Tabela 2. Estes dados auxiliaram na estimativa da liberação do $\mathrm{N}_{1} \mathrm{P}_{2} \mathrm{O}_{5}$ e $\mathrm{K}_{2} \mathrm{O}$, em função da utilização dos adubos orgânicos, desde que as condições estivessem ideais para a mineralização (RIBEIRO et al., 1999). Dessa forma, as planilhas realizam a recomendação para dois anos de cultivo em função da percentagem de mineralização no decorrer do tempo. Para cultivos posteriores é necessário realizar a análise do solo novamente.

Tabela 2: Percentagem de conversão dos nutrientes aplicados via fertilizantes orgânicos, para a forma mineral, em função do tempo.

\begin{tabular}{llll}
\hline \multirow{2}{*}{ Nutrientes } & \multicolumn{2}{l}{ Tempo de conversão } & Após o 20 ano \\
\cline { 2 - 4 } & 10 ano & 20 ano & 30 \\
$\mathrm{~N}$ & $\%$ & 20 & 20 \\
$\mathrm{P}_{2} \mathrm{O}_{5}$ & 50 & 20 & 0 \\
$\mathrm{~K}_{2} \mathrm{O}$ & 60 & 0 & \\
\hline
\end{tabular}

Para facilitar a escolha dos fertilizantes, adicionaram-se caixas de combinação, onde foram listados todos os fertilizantes, assim como, a vinculação das planilhas de culturas junto à planilha de análise do solo e a de fertilizantes, para a importação de valores e consequentemente a recomendação. Para realizar o cálculo de recomendação da adubação utilizou-se a ferramenta "Solver", a qual permitiu encontrar a melhor combinação de fertilizantes, de acordo com a exigência da cultura, pois esta ferramenta disponível no Excel permite manipular mais de uma variável por vez e definir restrições (CINTO et al., 2008).

Ao final do processo de recomendação da adubação, o resultado pode ser impresso ou salvo em PDF na área de trabalho. Para isso, utilizou-se o VBA para criação dos botões de "Imprimir" e "Salvar em PDF". O VBA trata-se de uma linguagem que tem a função de ampliar as potencialidades dos produtos do Microsoft Office (CINTO et al., 2008).

\section{RESULTADOS E DISCUSSÃO}

O aplicativo foi nomeado de 'Hortfértil' e possui 23 planilhas eletrônicas, dentre as quais, 14 podem ser acessadas pelo usuário e as demais são para cálculos e processamento de dados, como pode ser observado na figura 1.

Na planilha 'Menu' pode ser observado o nome do aplicativo e os quatro principais botões de navegação (Figura 2). Os botões e ícones foram criados por intermédio da ferramenta 'Hiperlink', o que possibilita criar botões que transferem o usuário de uma planilha para outra.

Ao clicar no botão 'Análise de solo', o usuário terá acesso a uma planilha para preenchimento dos dados de análise do solo (Figura 3), os quais serão importados para as planilhas de recomendação de adubação e utilizados como parâmetros para definir a quantidade ideal de fertilizantes a serem utilizados. Para evitar alterações acidentais nas planilhas, estas foram protegidas e apenas os campos editáveis foram 
liberados. Assim, apenas as células em branco estão liberadas para preenchimento.

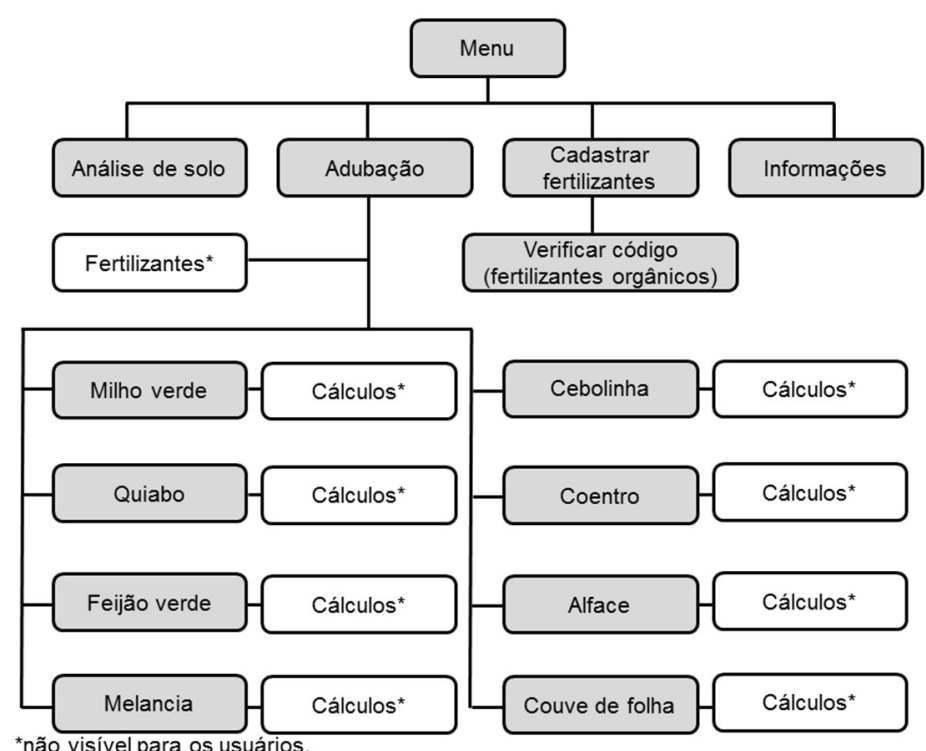

Figura 1: Fluxograma das planilhas eletrônicas presente no aplicativo.

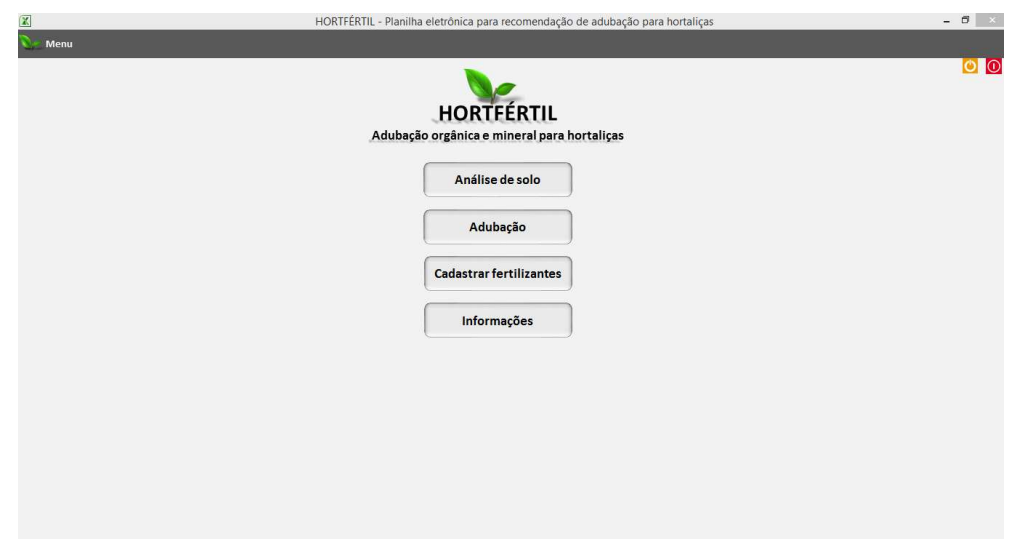

Figura 1: Menu principal do aplicativo.

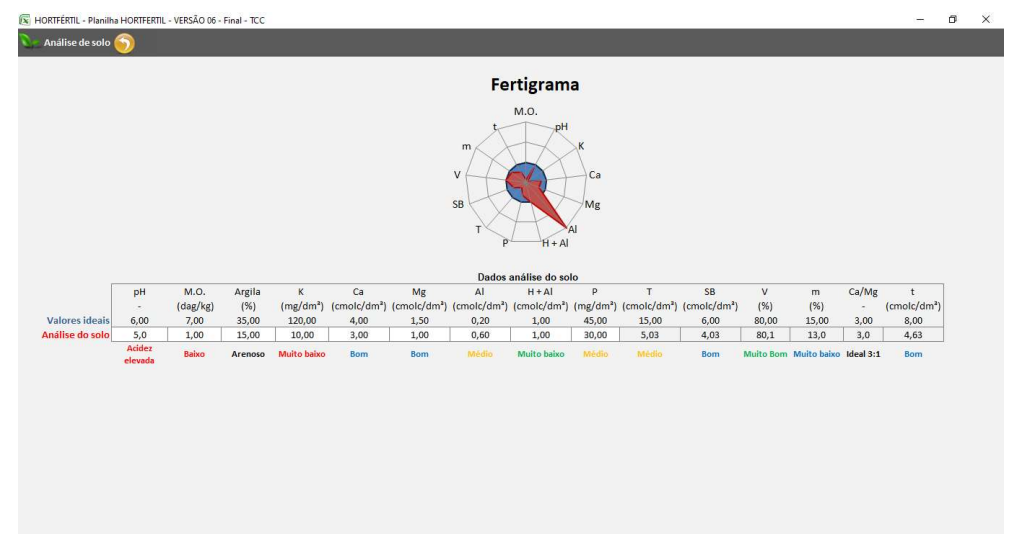

Figura 2: Planilha para preenchimento dos dados de análise do solo.

Para uma melhor visualização do comportamento dos dados da análise de solo, o usuário poderá observar no fertigrama os elementos limitantes da produção. A linha azul representa valores ideais preestabelecidos e a linha vermelha representa os valores atuais da análise do solo.

Ao clicar no botão 'Adubação' no menu principal, o usuário poderá escolher a cultura na qual deseja realizar a recomendação (Figura 4). 


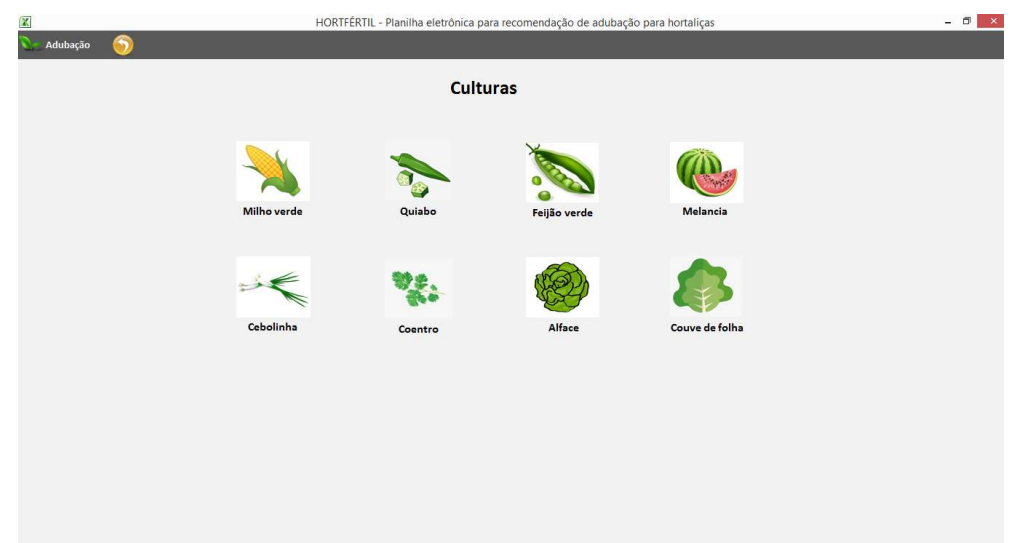

Figura 3: Planilha menu de culturas para recomendação de adubação.

Ao escolher a cultura desejada, uma planilha semelhante à figura 5 será aberta, com algumas características específicas para cada cultura. O usuário deverá preencher o nome do produtor, o espaçamento da cultura e a dimensão da sua área de trabalho, e automaticamente a planilha fornecerá a população de plantas por área.

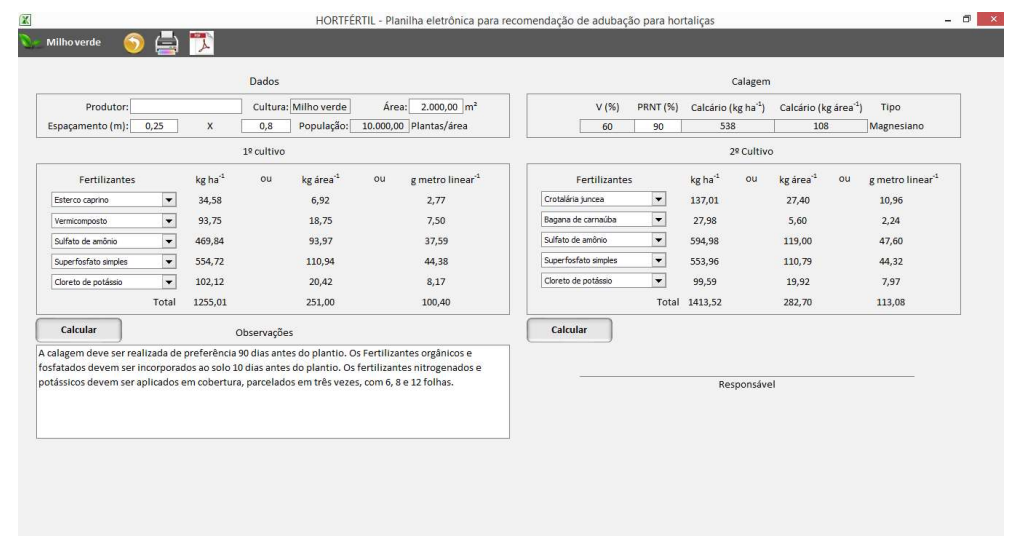

Figura 4: Planilha recomendação de adubação para o milho verde.

Para a recomendação de calagem o usuário deverá inserir o PRNT do calcário e a planilha retornará à quantidade de calcário recomendada em $\mathrm{kg}$ área-1 $\mathrm{e} \mathrm{em} \mathrm{kg} \mathrm{ha}^{-1}$, além do tipo de calcário ideal a ser utilizado. A saturação de bases ideal para cultura já se encontra preestabelecida na planilha, conforme recomendações de Ribeiro et al. (1999).

A planilha recomendará adubação para dois cultivos consecutivos. No primeiro cultivo a planilha recomenda adubação baseando-se exclusivamente na análise de solo, ao passo que os cálculos de segundo cultivo são baseados também, nas percentagens de conversão do fertilizante orgânico para a forma mineral, conforme estabelecidas por Ribeiro et al. (1999). Estes dados ajudam a estimar a liberação do $\mathrm{N}_{2} \mathrm{P}_{2} \mathrm{O}_{5}$ e $\mathrm{K}_{2} \mathrm{O}$ em função da utilização dos adubos orgânicos, desde que as condições estejam ideais para a mineralização. Além disso, nos cálculos são acrescentados os teores médios de umidade de cada fertilizante, tendo em vista que os teores médios encontrados na literatura são baseados na matéria seca.

A escolha dos fertilizantes é realizada nas caixas de combinação, onde estão listados todos os fertilizantes. Nas duas primeiras caixas de combinação estão listados os fertilizantes orgânicos e nas outras três os fertilizantes minerais. Ao escolher os fertilizantes e clicar no botão 'Calcular', os valores serão importados para as planilhas de cálculo referente a cada cultura, onde ocorrerão todos os cálculos 
necessários e apenas os valores recomendados são importados para a planilha de apresentação visualizada pelo usuário. A planilha retornará os valores recomendados em $\mathrm{kg} \mathrm{ha}^{-1}, \mathrm{~kg}$ área-1 $^{-1} \mathrm{e}$ em g metro linear ${ }^{-1}, \mathrm{~g} \mathrm{cova}^{-}$ ${ }^{1}$ ou $\mathrm{g} \mathrm{m}^{-2}$, dependendo da cultura.

Para importar os teores nutricionais da planilha de fertilizantes para a planilha de apresentação por intermédio da caixa de combinação, adotou-se a função 'Índice'. Está função retorna o valor de um elemento em uma tabela, selecionado pelos índices de número de linha e coluna (CINTO et al., 2008).

A função "Se" foi utilizada para analisar os dados nutricionais da análise de solo, compará-la com valores tabelados, classificados em baixo, médio, alto ou bom e, a partir daí decidir a quantidade de $\mathrm{N}, \mathrm{P}_{2} \mathrm{O}_{5}$ e $\mathrm{K}_{2} \mathrm{O}$ a ser utilizada nos cálculos, conforme recomendações de Ribeiro et al. (1999), Cravo et al. (2007) e Aguiar et al. (2014). Segundo Manzano (2010) esta função consegue analisar os dados, comparar grandezas e, a partir da comparação, auxiliar na tomada de decisão.

O cálculo de recomendação da adubação foi realizado por intermédio da ferramenta "Solver". Esta ferramenta permitiu manipular mais de uma variável por vez e definir restrições (CINTO et al., 2008). Para encontrar a melhor combinação de fertilizantes, foi definida como restrições as quantidades de $\mathrm{N}_{2} \mathrm{P}_{2} \mathrm{O}_{5}$ e $\mathrm{K}_{2} \mathrm{O}$ recomendada para as culturas em função dos teores nutricionais da análise do solo. Determinada as restrições, a ferramenta 'Solver' busca a melhor combinação de fertilizantes que atenda as exigências das culturas.

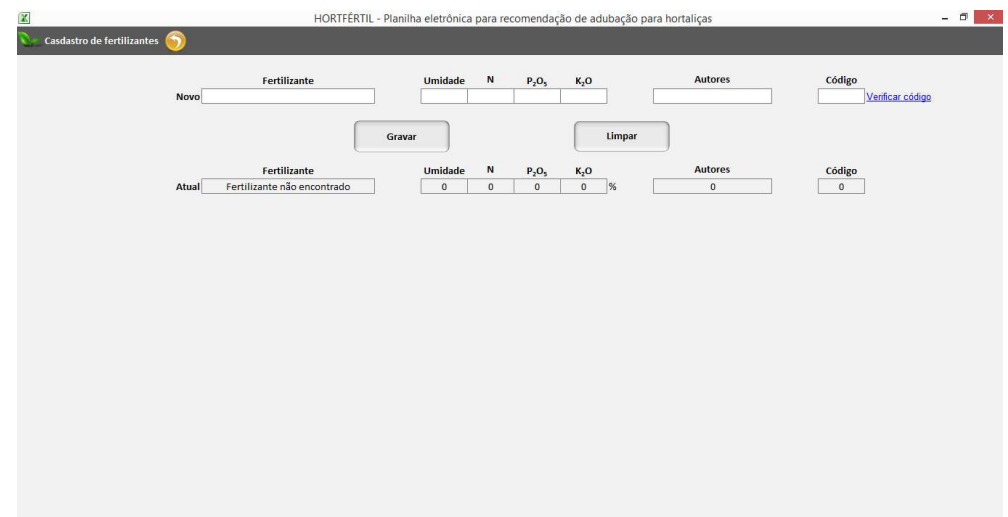

Figura 5: Planilha para cadastro de fertilizantes orgânicos.

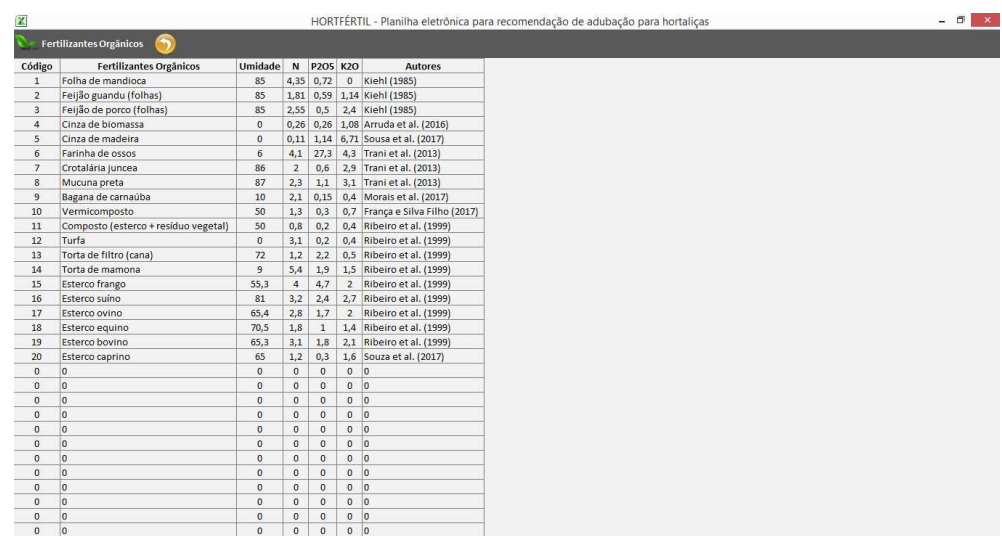

Figura 6: Planilha de fertilizantes orgânicos cadastrados.

As orientações como formas e épocas de aplicação dos fertilizantes, dentre outras informações podem ser acrescentadas no campo 'Observações', localizado na planilha de apresentação. O resultado da recomendação pode ser impresso ou salvo em PDF na área de trabalho. Para isso foram criados os botões 
'Imprimir' e 'Salvar em PDF' por meio da ferramenta VBA. A mesma ferramenta foi utilizada para deixar as planilhas em tela cheia, retirando a barra de ferramentas, barra de fórmulas, linhas de grade e títulos.

Ao clicar no botão 'Cadastrar fertilizantes' no menu principal, o usuário poderá cadastrar um novo fertilizante (Figura 6). Para realizar o cadastro, basta inserir um novo código, inserir o nome do fertilizante, teor de umidade, teores nutricionais e clicar no botão 'Gravar'. Para alterar um fertilizante já cadastrado, basta inserir o código do fertilizante e nas células em branco, realizar as alterações necessárias, simulando um novo cadastro. Para verificar o código do fertilizante a ser editado, basta clicar no link 'Verificar código' e o usuário terá acesso a planilha dos fertilizantes orgânicos (Figura 7). Todo o processo automatizado do cadastro de fertilizantes foi realizado com a criação de macros por meio do VBA.

Tendo em vista que os fertilizantes minerais apresentam garantias nutricionais já padronizadas, os mesmos já se encontram fixados na planilha de fertilizantes e não estão sujeitos a cadastros ou alterações.

\section{CONCLUSÕES}

O 'Hortfértil' apresenta-se como uma ferramenta promissora na recomendação de adubação orgânica e mineral, para hortaliças. Devido à complexidade de funcionamento exige um grande período de avaliação e experimentação para poder ser comprovada sua aplicabilidade e eficiência na recomendação de fertilizantes.

\section{REFERÊNCIAS}

AFFONSO, E. P.; HASHIMOTO, C. T.; SANT'ANA, R. C. G.. Uso de tecnología de la información en la agricultura familiar: Planilla para gestión de insumos. Biblios: Journal of Librarian ship and Information Science, v.60, n.01, p.45-54, 2015. DOI: http://doi.org/10.5195/biblios.2015.221

AGUIAR, T.; GONÇALVES, C.; PATERNIANI, M.; TUCCI, M.; CASTRO, C.. Boletim 200: instruções agrícolas para as principais culturas econômicas. Campinas: Instituto Agronômico, 2014.

ANDRADE, E. M. G.; SILVA, H. S.; SILVA, N. S.; SOUSA JÚNIOR, J. R.; FURTADO, G. F.. Adubação orgânomineral em hortaliças folhosas, frutos e raízes. Revista Verde, Mossoró, v.7, n.3, p.7-11, 2012.

ARRUDA, J. A.; AZEVEDO, T. A. O.; FREIRE, J. L. O.; BANDEIRA, L. B.; ESTRELA, J. W. M.; SANTOS, S. J. A.. Uso da cinza de biomassa na agricultura: efeitos sobre atributos do solo e resposta das culturas. Revista Princípia, João Pessoa, v.1, n.30, p.01-13, 2016.

BISSANI, C.; TEDESCO, M.; SELBACH, P. A.; SÁ, E. L. S.; GIANELLO, C.; CAMARGO, F. A. O.. Fertilidade dos solos e manejo da adubação das culturas. Porto Alegre: Gênesis, 2008.

CINTO, A. F.; GÓES, W. M.. Excel avançado. São Paulo: Novatec, 2008.

CRAVO, M. S.; VIÉGAS, I. J. M.; BRASIL, E. C.. Recomendações de adubação e calagem para o Estado do Pará. Belém: Embrapa Amazônia Oriental, 2007.
DIAS, R. E. B. A.; DIAS, R. A. A.; PRADO, A. S.; FIGUEIREDO, F. C.; PEREIRA, S. P.; DELAVIA, F. S.. Desenvolvimento de software de interpretação e análise de solo e recomendação de corretivos e fertilizantes para o cafeeiro. In: SIMPÓSIO DE PESQUISA DOS CAFÉS DO BRASIL, 7. Anais. Araxá: SPCB, 2011.

FERRAZ, C. O.; PINTO, W. F.. Tecnologia da informação para a agropecuária: Utilização de ferramentas da tecnologia da informação no apoio a tomada de decisões em pequenas propriedades. Revista Eletrônica Competências Digitais para Agricultura Familiar, Tupã, v.3, n.1, p.38-49, 2017.

KIEHL, J. E.. Fertilizantes orgânicos. Piracicaba: Agronômica Ceres, 1985.

LIMA, P. C.; MOURA, W. M.; SEDIYAMA, M. A. N.; SANTOS, R. H. S.; MOREIRA, C. L.. Manejo da adubação em sistemas orgânicos. In: LIMA, P. C.; MOURA, W. M.; VENZON, M.; PAULA JUNIOR, T.; FONSECA, M. C. M.. Tecnologias para produção orgânica. Viçosa: Unidade Regional EPAMIG Zona da Mata, 2011. p.69-106.

MANZANO, A. L. N. G.. Estudo dirigido de Microsoft Office Excel 2010. São Paulo: Érica, 2010.

MORAIS, M. C.; ARAÚJO JUNIOR, B. B.; FARIAS, B. L. A.. Palha de carnaúba incorporada ao solo para fertilização no cultivo orgânico de cenoura. Revista Verde de Agroecologia e Desenvolvimento Sustentável, Pombal, v.12, n.4, p.820-823, 2017. DOI: http://dx.doi.org/10.18378/rvads.v12i4.4908 
NASCIMENTO, P. S.; BASSOI, L. H.; PAZ, V. P. S.. Planilha eletrônica para auxílio à tomada de decisão em manejo de irrigação. Revista Irriga, Botucatu, v.17, n.1, p.1-15, 2012. DOI: https://doi.org/10.15809/irriga.2012v17n1p01

PEREIRA, D. C.; NETO, A. W.; NÓBREGA, L. H. P.. Adubação orgânica e algumas aplicações agrícolas. Revista Varia Scientia Agrárias, Cascavel, v.3, n.2, p.159-174, 2013.

RIBEIRO, A. C.; GUIMARÃES, P. T. G.; ALVARES V, V. $H$.. Recomendações para o uso de corretivos e fertilizantes em Minas Gerais: 5. Aproximação. Viçosa: CFSEMG, 1999.

SEDIYAMA, M. A. N.; MAGALHÃES, I. P. B.; VIDIGAL, S. M.; PINTO, C. L. O.; CARDOSO, D. S. C. P.; FONSECA, M. C. M.; CARVALHO, I. P. L.. Uso de fertilizantes orgânicos no cultivo de alface americana (Lactuca sativa L.) 'Kaiser'. Revista Brasileira de Agropecuária Sustentável, Viçosa, v.6, n.2, p.66-74, 2016. DOI:

http://dx.doi.org/10.21206/rbas.v6i2.308

SEDIYAMA, M. A. N.; SANTOS, I. C.; LIMA, P. C.. Cultivo de hortaliças no sistema orgânico. Revista Ceres, Viçosa, v.61, n.7, p.829-837, 2014. DOI: https://doi.org/10.1590/0034$737 \times 201461000008$

SOUSA, L. F. R. A.; SILVA, W. A.; SILVA, R. V.. Desenvolvimento de um aplicativo computacional para a recomendação de adubação e calagem para a cultura do milho (Zeamays L.) no estado do Maranhão, Brasil. Revista Agroecossistemas, Belém, v.3, n.1, p.36-40, 2011. DOI: http://dx.doi.org/10.18542/ragros.v3i1.1368

SOUSA, P. G. R.; SOUSA, J. P. F.; SOUSA, A. M.; COSTA, R. N. T.. Produtividade do mamoeiro cultivado sob aplicação de cinzas vegetais e bagana de carnaúba. Revista Brasileira de Agricultura Irrigada, Fortaleza, v.11, n.1, p.120 -1212, 2017a. DOI: http://dx.doi.org/10.7127/rbai.v11n100565

SOUZA, F. M.; LIMA, E. C. S.; SÁ, F. V. S.; SOUTO, L. S.; ARAÚJO, J. E. S.; PAIVA, E. P.. Crescimento inicial do milho sob doses de esterco caprino e disponibilidade de água no solo. Revista Verde de Agroecologia e Desenvolvimento Sustentável, Pombal, v.12, n.2, p.241-245, 2017b. DOI: http://dx.doi.org/10.18378/rvads.v12i2.4964

TRANI, P. E.; TERRA, M. M.; TECCHIO, M. A.; TEIXEIRA, L. A. J.; HANASIRO, J.. Adubação Orgânica de Hortaliças e Frutíferas. Campinas: Instituto Agronômico, 2013.

ZANDONADI, D. B.; SANTOS, M. P.; MEDICI, L. O.; SILVA, J. D.. Ação da matéria orgânica e suas frações sobre a fisiologia de hortaliças. Horticultura Brasileira, Brasília, v.32, n.1, p.1420, 2014. http://dx.doi.org/10.1590/S0102 05362014000100003 